Pol. J. Food Nutr. Sci., 2020, Vol. 70, No. 3, pp. 233-240

DOI: $10.31883 /$ pjfns/120915 http://journal.pan.olsztyn.pl

Original research article

Food Quality and Functionality Section

\title{
Influence of $\beta$-Glucan Structures and Contents on the Functional Properties of Low-Fat Ice Cream During Storage
}

\author{
Marek Aljewicz*, Aleksandra Florczuk, Aneta Dąbrowska \\ Department of Dairy Science and Quality Management, Faculty of Food Science, University \\ of Warmia and Mazury in Olsztyn, Oczapowskiego 7, 10-719 Olsztyn, Poland
}

Key words: polysaccharides, milk dessert, curdlan, rheology, texture, sensory analysis

The study aimed to determine the effect of the addition level and structure of $\beta$-glucans on the functional properties and sensory attributes of low-fat ice cream. The experimental ice cream was produced with the addition of $0.5 \%$ and $1 \%$ highly purified (1-3)(1-4) and (1-3) $\beta$-glucans.

$\beta$-Glucans significantly increased overrun and decreased the melting time. The study demonstrated that the $\beta$-glucan structure and addition level significantly influenced the consistency and viscosity index, flow behavior, cohesiveness, and firmness of ice cream. The use of (1-3)(1-4) $\beta$-glucan led to a significant decrease $(\sim 38 \%)$, whereas (1-3) $\beta$-glucan led to a significant increase $(\sim 42 \%)$ of ice cream firmness. $\beta$-Glucans influenced the sensory properties of ice cream, in particular its texture and mouthfeel but had no significant effect on the taste of ice cream. (1-3)(1-4) $\beta$-Glucan isolated from oats is suitable for the production of calorie-reduced ice cream with functional characteristics most similar to the control ice cream (full-fat, with stabilizing substances).

\section{INTRODUCTION}

Ice cream is an emulsion $(\mathrm{o} / \mathrm{w})$ that contains air bubbles, partially coalesced fat globules and ice crystals. These components are dispersed in a viscous liquid phase composed of proteins, minerals, and polysaccharides that stabilize the emulsion [Soukoulis et al., 2010]. The rheological properties of ice cream, including texture and microstructure, are determined by the composition of the ice cream mixture, in particular its fat content that ranges from $8 \%$ to $16 \%$. In ice cream, fat is responsible for the production of emulsion, for the size and shape of ice crystals, and melting time. Reduced fat content can increase the brittleness and roughness of ice cream. In addition to shaping the rheological properties of ice cream, dairy fat is also a flavor carrier contributing to their full and creamy taste [Bahramparvar \& Tehrani, 2011].

The rise in consumer awareness about the nutritional and biological value of foods, as well as changing nutritional trends, encourage food manufacturers to develop new production technologies. Low-calorie foods containing only natural ingredients are in most significant demand. According to many authors, the energy value of foods can be reduced through the partial replacement of fat with polysaccharides, which effectively imitate fat on account of their unique functional properties [Javidi et al., 2016]. The ideal fat replacer should not only decrease a product's energy value,

\footnotetext{
* Corresponding Author: E-mail: marek.aljewicz@gmail.com (M. Aljewicz)
}

but it should also exert minimal influence on the functional properties and the sensory attributes of ice cream. Polysaccharides, including guar gum [Javidi \& Razavi, 2018], maltodextrin and polydextrose [Güzeler et al., 2011], fructooligosaccharides [Akalin et al., 2008; Soukoulis et al., 2010], dietary fiber from cereals and citrus fruit [Soukoulis et al., 2010], starch [Sharma et al., 2017], and barley $\beta$-glucan [Abdel-Haleem \& Awad, 2015], are most widely used as fat mimetics in the production of ice cream. $\beta$-Glucans are highly interesting fat mimetics in the production of ice cream and other dairy products. Unlike other polysaccharide replacers, they deliver health benefits by decreasing the risk of diet-dependent diseases such as hyperinsulinemia, hyperlipidemia, impaired immunity [Kanagasabapathy et al., 2013], and osteoporosis [Aljewicz et al., 2018]. $\beta$-Glucans isolated from various sources differ in structure, namely the presence and distribution of glycosidic bonds and molecular weight [Stone, 2009]. $\beta$-Glucans isolated from mushrooms are characterized by the highest molecular weight $\left(2-3 \times 10^{6} \mathrm{~g} / \mathrm{mol}\right)$, whereas these isolated from bacteria and oats have a lower molecular weight at $0.66 \times 10^{5} \mathrm{~g} / \mathrm{mol}$ and $0.56 \times 10^{5} \mathrm{~g} / \mathrm{mol}$, respectively [Survase et al., 2007]. Due to their high molecular weight, $\beta$-glucans are better thickening agents than other polysaccharides, and they reduce the amount of other ingredients in food production.

Despite the above, there is a general scarcity of published research on the suitability of $\beta$-glucans for ice cream production. The effect of the addition level and structure of polysaccharides, including highly purified $\beta$-glucan preparations, on 
the functional properties of low-fat ice cream has never been investigated. Therefore, the aim of this study was to determine the influence of $\beta$-glucans structure and content level on the functional properties and sensory attributes of low-fat ice cream.

\section{MATERIALS AND METHODS}

\section{Materials and sample preparation}

The study was performed on control ice cream with $10 \%$ fat content (typical fat content of full-fat ice cream on the Polish market). In experimental (low-fat) ice cream, the fat content was reduced to $2.5 \%$ in order to determine the possibility of replacing fat with $0.5 \%$ and $1 \%$ addition of $\beta$-glucans. The experimental ice cream was produced with the addition of highly purified (75\%) (1-3)(1-4) $\beta$-glucan isolated from oats Avena sativa L. (Beta Bio Technology, Poland) and highly purified (90\%) (1-3) $\beta$-glucan (curdlan) isolated from Agrobacterium sp. bacteria (Xi'an Lyphar Biotech Co., Ltd, China). The $\beta$-glucans content of the preparation was based on a certificate provided by the manufacturer. The addition of (1-3) (1-4) $\beta$-glucan was normalized to ensure that $\beta$-glucans content was identical to that of the experimental ice cream containing (1-3) $\beta$-glucan. Samples of ice cream stored at $-18^{\circ} \mathrm{C}$ for 1 day and 14 days were collected for analysis.

\section{Ice cream production}

The following ingredients were used in ice cream production: deionized water, dehydrated milk fat $(10 \%$ $w / w$ in the control ice cream; $2.5 \% w / w$ in the experimental ice cream; Supply Group BV, Maasland, Netherlands), skimmed milk powder $(8.5 \% \mathrm{w} / \mathrm{w}$ in the control ice cream; $\sim 17 \%$ $w / w$ in the experimental ice cream; Gostynin, Poland), whey protein isolate (3\% w/w; Fonterra, Auckland, New Zealand), sucrose ( $8 \% w / w$; Poch, Gliwice, Poland), glucose in powder (3\% w/w; Poch, Gliwice, Poland), and lecithin $(0.5 \% \mathrm{w} / \mathrm{w}$; Sigma-Aldrich, Schnelldorf, Germany). The control ice cream contained a stabilizer $(0.3 \% \mathrm{w} / \mathrm{w}$, blend of locust bean gum, guar gum, and carrageenan), whereas the experimental ice cream contained $0.5 \%$ or $1 \%$ of (1-3)(1-4) $\beta$-glucan or (1-3) $\beta$-glucan. The experimental ice cream was produced based on Patent Application P.418827 [2020]. The prepared sample was high-shear dispersed at 10,000 rpm for $3 \mathrm{~min}$ and pasteurized at $95^{\circ} \mathrm{C}$ for $15 \mathrm{~min}$. Ice cream emulsions were prepared with the use of a multifunctional device (Rpol, Mielec, Poland). After preparation, the mixtures were cooled to $4 \pm 1^{\circ} \mathrm{C}$ in an ice-water bath and aged overnight at $4^{\circ} \mathrm{C}$ in a cooler. Continuous freezing was performed in a professional ice cream maker (Easy Freeze 1000; Promag, Anzola dell'Emilia, Italy). All samples were frozen at $-18^{\circ} \mathrm{C}$ in $100-\mathrm{mL}$ hinged-lid polypropylene containers and analyzed after 1 and 14 days. The ice cream was produced on the same day.

\section{Analyses of physical properties}

\section{Chemical composition analysis}

Ice cream samples were analyzed for the content of total solids [AOAC, 2000; method 941.08] and protein [EN ISO 8968-1:2014].

\section{Overrun and melting properties}

Overrun (\%) was determined according to the method described by Rinaldi et al. [2014]. A volume of liquid mix and ice cream was weighed, and percentage of overrun was calculated according to the equation:

$$
\operatorname{Overrun}(\%)=\frac{\mathrm{m}_{\text {ice cream mix }}-\mathrm{m}_{\text {ice cream }}}{\mathrm{m}_{\text {ice cream mix }}}
$$

where: $\mathrm{m}_{\text {ice cream mix }}$ was the weight of mix and $\mathrm{m}_{\text {ice cream }}$ the weight of ice cream after freezing.

Melting time was determined according to the method described by Granger et al. [2005]. The overrun and melting time properties of each ice cream sample were measured in three replications.

\section{Viscosity and flow behavior of emulsions}

The viscosity of the ice cream emulsions was determined after $3 \mathrm{~h}$ of aging at $4 \pm 1^{\circ} \mathrm{C}$ with the RheolabQC Viscometer (Anton Paar GmbH, Ostfildern, Germany) equipped with a cooling/heating circulator (Model F12-MC, Julabo Labor Technik, Seelbach, Germany) and the CC27 measuring system. The samples were allowed to stand for $3 \mathrm{~min}$ before analysis. Twenty-nine viscosity values were measured and recorded (PhysicaRheo Plus software; Anton Paar $\mathrm{GmbH}$, Ostfildern, Germany) at intervals of $51 / \mathrm{s}$ to create a range of shear rates from 0 to $150 \mathrm{1} / \mathrm{s}$. The viscosity at a shear rate of $6.32 \mathrm{1} / \mathrm{s}$ was used for comparison (the value closest to the conditions in the oral environment during chewing). Rheological properties were fitted to two rheological models, including Herschel-Bulkley and Ostwald models. The Herschel-Bulkley model produced the best fit to upward flow curves (results not shown), and it was selected for modeling flow behavior:

Herschel-Bulkley model:

$$
\tau=\tau_{0}+\mathrm{k}(\gamma)^{\mathrm{n}}
$$

where: $\tau$ is shear stress $(\mathrm{Pa}), \mathrm{k}$ is the consistency index $\left(\mathrm{Pa} \cdot \mathrm{s}^{\mathrm{n}}\right)$, $\gamma$ is shear rate $(1 / s), \tau_{0}$ is yield stress, and $n$ is the flow behavior index (dimensionless). The viscosity of each ice cream sample was measured in three replications.

\section{Texture analysis of ice cream}

An instrumental back extrusion test was performed using the TA-XT-plus Texture Analyzer (Stable Micro Systems, Surrey, UK) equipped with a 5-mm diameter stainless steel cylindrical probe. The following test settings were applied: penetrating distance $=15 \mathrm{~mm}$, force $=5 \mathrm{~g}$, probe speed during penetration $=3.3 \mathrm{~mm} / \mathrm{s}$, and probe speed before and after penetration $=3 \mathrm{~mm} / \mathrm{s}$. Tests were performed immediately after ice cream samples were removed from the freezer, and the time interval for the analysis was standardized. The samples were stored at $-12^{\circ} \mathrm{C}$ for $24 \mathrm{~h}$ before analysis. The analyses were performed at $20 \pm 1^{\circ} \mathrm{C}$. The force-time curves were analyzed using Texture Exponent. The texture of each ice cream sample was measured in six replications. 


\section{Color analysis}

The instrumental color analysis was performed with the CR-400 Chroma Meter (Konica Minolta, Ramsey, USA). The values of $\mathrm{L}^{*}, \mathrm{a}^{*}$ and $\mathrm{b}^{*}$ color parameters were measured. Individual ice cream samples were placed in a Petri dish. The device was calibrated before the test using the white and black standard included in the measurement set. Sample temperature was equal to the ambient temperature $\left(20 \pm 1^{\circ} \mathrm{C}\right)$. The color of each ice cream sample was measured in six replications.

\section{Sensory analysis}

The sensory attributes of ice cream samples were analyzed in a dedicated laboratory by sensory profiling using a five-point descriptive scale, according to ISO Standard method [EN ISO 13299:2016]. The evaluation was carried out by a panel of eight suitably trained persons with the appropriate sensory sensitivity, according to ISO Standard method [EN ISO 8586:2014]. Before the main sensory test, three 2-h sessions were conducted for the panelists with the use of commercial ice cream, milk, cream, milk powder, and flavor substances. Each sample was coded using a three-digit random number and served in $100 \mathrm{~mL}$ transparent hinged-led propylene containers. During the sensory analysis, each of the panelists was provided with a definition card and a product evaluation card. The cards contained a total of 28 attributes. Each attribute was defined. Individual sensory attributes were assessed using a five-point descriptive scale from 1 to 5 . The intensity of a given sensory attribute was tested, where 1 denoted the absence of a given attribute, and 5 denote attribute of extreme intensity. The sensory attributes of ice cream samples were analyzed once after 14 days of storage.

\section{Statistical analysis}

The results were verified for normal distribution and homogeneity of variance. In physio-chemical analyses, the significance of differences between means was analyzed by Tukey's test and the interactions between factors (storage time, addition level and structure of $\beta$-glucans, and the interactions between factors) were determined by two-way ANOVA. At this stage, data were presented as means \pm standard deviation. The experiment was performed in duplicate. The results of the sensory evaluation were analyzed using one-way ANOVA. Fisher's LSD tests were carried out to determine statistical differences between mean values within individual attributes. All results were processed in Statistica 13.5 PL software (Statsoft 2017, Krakow, Poland) at 0.05 significance level.

\section{RESULTS AND DISCUSSION}

In frozen dairy desserts, the sensory attributes and, consequently, the consumer acceptability of the final product are determined by fat content, the distribution of fat in the product, but also by the functional additives used during production. Other research studies have demonstrated that the application of inulin or oligofructose [Akalin \& Erisir, 2008; Karaca et al., 2009] significantly increased ice cream aeration.

The average overrun was determined at $63.53 \%$ in the control ice cream and increased significantly by $\sim 17 \%$ in the samples containing $0.5 \%$ of $\beta$-glucans. Higher overrun resulted from an increase in the viscosity of the ice cream mix as well as the fact that the minimal boundary that guarantees the system's stability and the production of a thin film between air bubbles was exceeded. The system was additionally stabilized by the presence of whey proteins and $\beta$-glucans that decreased its surface tension [Burkus \& Temelli, 2000]. In fresh ice cream, the overrun decreased (approximately $4 \%$ ) when the content of $\beta$-glucans increased from $0.5 \%$ to $1 \%$, but the changes were insignificant. Storage time had no significant influence on overrun $(p>0.05)$ (Table 1). Despite the above, an increase in overrun is not identical for all polysaccharides. The addition of guar gum and basil seed gum [Javidi et al., 2016] in ice cream production decreased aeration. The above differences could be attributed to variations in the structure and the functional attributes of the analyzed additives, including their hygroscopic properties.

The use of the $\beta$-glucans additive resulted in a significant $(p<0.001)$ change in the melting time of ice cream (Table 1). In fresh ice cream with $0.5 \%$ addition of $\beta$-glucans, a significant (about $13 \mathrm{~min}$ ) shortening of ice cream melting time was observed. A reduction in the melting time was also found in ice-cream with $1 \%$ of $\beta$-glucans. However, these changes were not significant. A significant increase in the melting time of ice cream was found in ice cream with $0.5 \%$ of (1-3)(1-4) $\beta$-glucan and $1 \%$ of (1-3) $\beta$-glucan after storage. The change of melting time during storage was most probably caused by slow absorption of free water by polysaccharide and formation of a more stable polysaccharide network. Overrun, the type of applied ingredients, the size of ice crystals, fat content, and the degree of fat destabilization influence the thermal stability of ice cream and, consequently, its melting time [Rezaei et al., 2015]. Similar results were obtained in a study by Dymitrów et al. [2012] where the ice cream melting time increased with a decrease in fat content and a decrease in fat destabilization [Bolliger et al., 2000]. Abdel-Haleem \& Awad [2015] also observed that the application of barley (1-3) (1-4) $\beta$-glucan in the production of low-fat ice cream decreased the melting time, which was attributed to a higher ice cream freezing temperature. The application of maltodextrin and polydextrose in the ice cream production process also increased the melting time [Roland et al., 1999]. Contrary results were reported by Florowska et al. [2013], where the addition of inulin prolonged ice cream melting. The above authors suggested that prolonged melting was associated with the water-binding capacity of polysaccharide molecules. It should also be noted that Florowska et al. [2013] analyzed ice cream samples with $20 \%$ fat content and $16.5 \%$ sugar content. However, the melting time of ice cream is more likely to be influenced by the product's chemical composition and the above factors than the hygroscopic properties of hydrocolloids.

Firmness is yet another structural attribute of ice cream. The texture analysis demonstrated that ice cream firmness was significantly $(\mathrm{p}<0.001)$ determined by the structure and content level of $\beta$-glucans (Table 1 ). The $0.5 \%$ addition of $(1-3)(1-4) \beta$-glucan led to a significant decrease in ice cream firmness by $45 \%$. Firmness increased by an additional $102 \%$ in the samples containing $1 \%$ of $(1-3) \beta$-glucan in comparison to ice cream containing $0.5 \%$ of (1-3) $\beta$-glucan. 


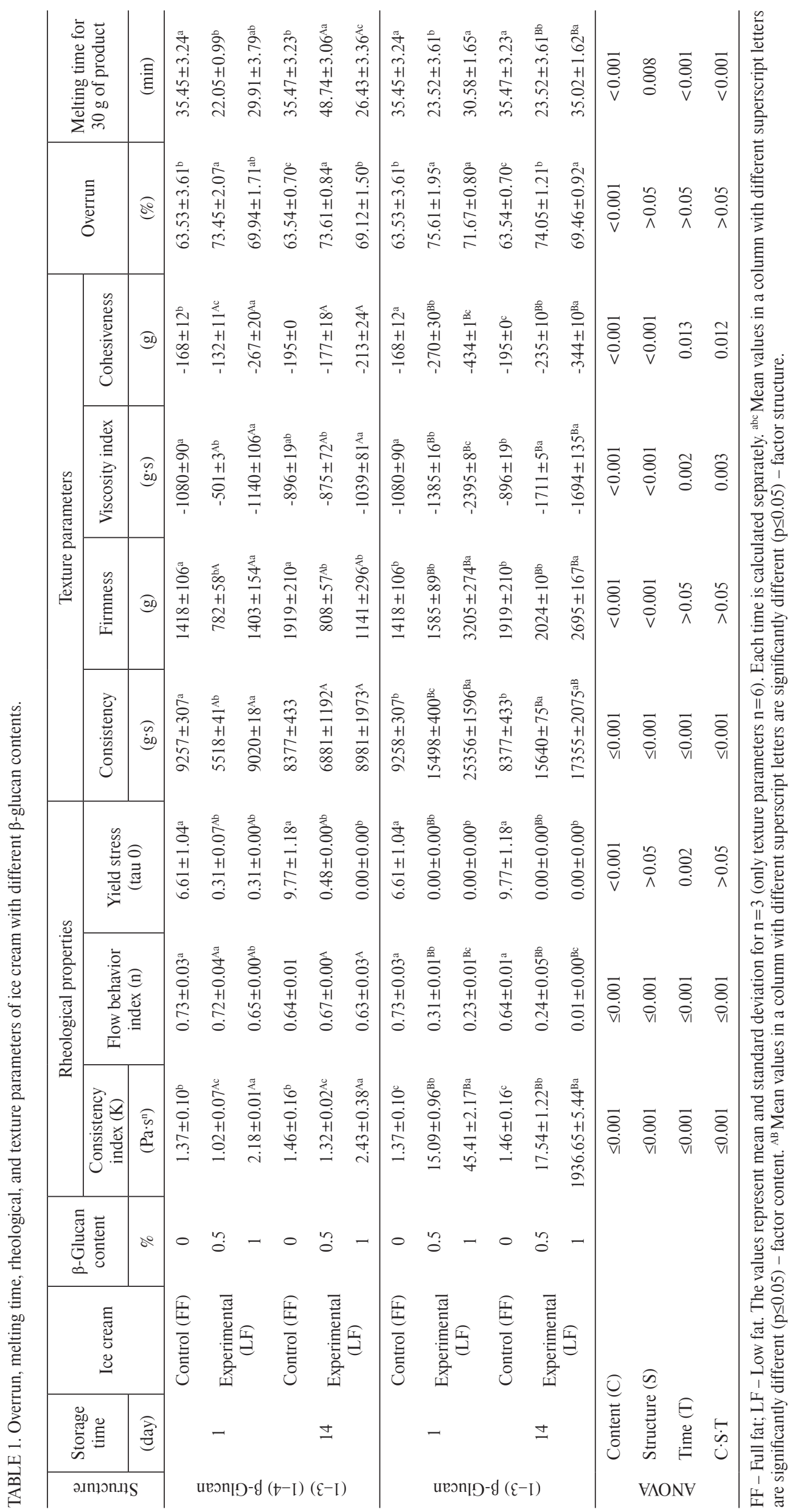


TABLE 2. Color $\left(L^{*}, a^{*}, b^{*}, \Delta E\right)$ characteristics of ice cream.

\begin{tabular}{|c|c|c|c|c|c|c|}
\hline \multirow{2}{*}{ Ice cream } & \multirow{2}{*}{$\begin{array}{l}\beta \text {-Glucan } \\
\text { structure }\end{array}$} & \multirow{2}{*}{$\begin{array}{c}\beta \text {-Glucan } \\
\text { content }(\%)\end{array}$} & \multicolumn{4}{|c|}{ Color analysis } \\
\hline & & & ${ }^{*} \mathrm{~L}$ & $* a$ & *b & $\Delta \mathrm{E}$ \\
\hline Control (FF) & & 0 & $88.44 \pm 0.51^{\mathrm{a}}$ & $-2.95 \pm 0.12^{\mathrm{a}}$ & $12.44 \pm 0.39^{\mathrm{a}}$ & 0 \\
\hline \multirow{4}{*}{ Experimental (LF) } & \multirow{2}{*}{$(1-3)(1-4)$} & 0.5 & $85.97 \pm 0.97^{b}$ & $-2.87 \pm 0.17^{\mathrm{Aa}}$ & $7.82 \pm 1.21^{\mathrm{Bc}}$ & 5.24 \\
\hline & & 1 & $83.27 \pm 0.31^{\mathrm{Bc}}$ & $-3.59 \pm 0.07^{\mathrm{b}}$ & $10.12 \pm 0.49^{b}$ & 5.71 \\
\hline & \multirow{2}{*}{$(1-3)$} & 0.5 & $85.70 \pm 0.14^{b}$ & $-3.46 \pm 0.09^{\mathrm{Bb}}$ & $12.05 \pm 0.31^{\mathrm{A}}$ & 2.82 \\
\hline & & 1 & $85.40 \pm 0.25^{\mathrm{Ac}}$ & $-3.76 \pm 0.05^{\mathrm{c}}$ & $11.83 \pm 0.47$ & 3.21 \\
\hline
\end{tabular}

The values represent mean and standard deviation for $n=3$. abc Mean values in column with different superscript letters are significantly different $(\mathrm{p} \leq 0.05)$ - factor content. ${ }^{\mathrm{AB}}$ Mean values in column with different superscript letters are significantly different $(\mathrm{p} \leq 0.05)$ - factor structure. Legend: FF - full fat; LF - low fat; $L^{*}$ - brightness, values between 0 (black) and 100 (white); $\mathrm{a}^{*}$ - value between -120 (red) and +120 (green) on the red and green; $b^{*}-$ value between -120 (blue) and +120 (yellow) on the blue and yellow; $\Delta \mathrm{E}$ - total colour difference.

Like in the current study, the addition of inulin (2-9\%) to ice cream in low-fat ice cream decreased firmness, which was attributed to the higher overrun of ice cream and inulin's higher water absorption capacity and lower freezing temperature [Bahramparvar \& Tehrani, 2011]. Contrary results were reported by Javidi et al. [2016] and Soukoulis et al. [2010], where the addition of other hygroscopic fat replacers, including basil seed gum, guar gum, fructooligosaccharides, and maltodextrin, to ice cream increased their firmness. The application of $\beta$-glucans with a linear structure increased the melting time and aeration, decreased elasticity, and increased instrumentally measured firmness relative to the samples containing $\beta$-glucans with a branched structure. ANOVA analysis revealed that consistency and the viscosity index were significantly determined by the structure and content level of the added $\beta$-glucans. The samples containing (1-3) $\beta$-glucan were characterized by a higher viscosity index, which was proportional to the content of the applied additive. Our results corroborate the findings of other authors [Hu et al., 2015]. In contrast, the 5\% addition of modified starch caused a significant decrease (by approx. 80\%) in the viscosity index of ice cream. The consistency changed significantly $(\mathrm{p} \leq 0.001)$ by $-40 \%$ and $+67 \%$ after the addition of $0.5 \%$ of $(1-3)(1-4)$ and (1-3) $\beta$-glucans relative to the control ice cream. In ice cream containing $1 \%$ of (1-3) $\beta$-glucan, the consistency increased significantly by $173 \%$ in comparison with the control ice cream (Table 1).

The analysis of rheological models demonstrated that the Herschel-Bulkley model was characterized by the highest coefficient of determination $\left(0.99 \leq \mathrm{r}^{2} \leq 0.999\right)$. The rheological analysis and the back-extrusion tests revealed that the content level and structure of $\beta$-glucans, as well as storage time significantly $(\mathrm{p}<0.001)$ influenced the consistency index of ice cream. The $1 \%$ addition of (1-3)(1-4) $\beta$-glucan contributed to a significant $(\mathrm{p} \leq 0.05)$ increase (by $60 \%$ and $66 \%$ in fresh and 14-day stored, respectively) in the consistency index. In fresh samples containing $0.5 \%$ and $1 \%$ of (1-3) $\beta$-glucans, the consistency index increased significantly $(\mathrm{p}<0.001)$ by $1100 \%$ and $3315 \%$, respectively, relative to the control ice cream. The flow behavior index was significantly affected by the structure, content of $\beta$-glucan as well as storage time. The $1 \%$ addition of (1-3) $\beta$-glucan de- creased the flow behavior index by $-69 \%(\mathrm{p}<0.001)$ relative to the fresh control ice cream $(0.734)$ and by $-12 \%$ relative to the samples containing (1-3)(1-4) $\beta$-glucan. The consistency index increased with an increase in $\beta$-glucans content, and similar results were reported by Simsekli \& Dogan [2015]. $\beta$-Glucans and other polysaccharides bind water molecules, which form small crystals. During the production process, crystals form larger aggregates that absorb water and increase the viscosity index of the ice cream. As a result, the viscosity of low-fat ice cream is equal to higher than that noted in full-fat ice cream [Akalin \& Erisir, 2008; Karaca et al., 2009, Rezaei et al., 2015]. The higher value of the consistency index in ice cream containing (1-3) $\beta$-glucan also resulted from differences in the $\beta$-glucan structure. Unlike (1-3) $\beta$-glucan, (1-3) (1-4) $\beta$-glucan (similarly to inulin) induces the formation of water gels with considerable viscosity, but lower firmness [Stone, 2009].

Regardless of their level, $\beta$-glucans caused significant differences in the color of all experimental samples (Table 2). In comparison with the control ice cream, samples with the addition of (1-3) (1-4) and (1-3) $\beta$-glucans were characterized by higher values of $\Delta \mathrm{E}$, determined at $5.24 \%$ and $2.82 \%$ in ice cream containing $0.5 \%$ of the additive, respectively, and at $5.71 \%$ and $3.21 \%$ in ice cream containing $1 \%$ of the additive. The addition of $\beta$-glucans resulted in significant changes in ice creams color, including decreased values of $a^{*}$ (the exception was ice cream with $0.5 \%$ of (1-3)(1-4) $\beta$-glucan). Only the (1-3)(1-4) $\beta$-glucan caused a significant decrease in the *b parameter. In other studies, the application of soy protein isolate [Akesowan, 2009] and citrus fiber [Dervisoglu \& Yazici, 2006] also induced changes in the value of $a^{*}$ (greenness). The value of $\mathrm{L}^{*}$ was higher in the control sample than in the experimental samples (containing $\beta$-glucans). The decrease in the lightness $L^{*}$ of the experimental ice cream resulted from the application of $\beta$-glucans. However, it could also be caused by the interactions between ice cream ingredients (mainly sugars and amino acids), which formed dark pigments (melanoidins) during thermal processing (preparation and pasteurization of the mixture) [Akesowan, 2009] and were undetectable to the naked eye.

Five groups of attributes were evaluated in the sensory analysis of ice cream: appearance, aroma, texture, mouthfeel, 
and taste. The structure and content level of $\beta$-glucans had no significant $(p>0.05)$ influence on color intensity or color uniformity of ice cream. Undesirable sensory attributes of appearance, such as discoloration or atypical color, were not observed in any of the examined samples (Table 3). The digital image analysis revealed minor $(\mathrm{p} \leq 0.05)$ changes in color, but these changes were too small to be identified by the panelists during the sensory analysis. Similar observations were made by Surapat \& Rugthavon [2003] in whose study, the application of modified starch did not change the color of ice cream. In an experiment conducted by Abdel-Haleem \& Awad [2015], the color of the experimental ice cream did not change after the addition of $0.4 \%$ of barley $\beta$-glucan. The above authors also demonstrated that the $0.4 \%$ addition of barley $\beta$-glucan and $1 \%$ and $2 \%$ addition of hulless barley flour to low-fat ice cream did not significantly alter its aroma. In the present study, a reduction in the fat content of ice cream decreased the intensity of the milky or sweet aroma. The milky aroma was most distinctive in the control sample and the sample containing $0.5 \%$ of $(1-3)(1-4) \beta$-glucan. A moderately perceptible milky aroma characterized the remaining samples. The sweet aroma was less intense in ice cream with the addition of (1-3) $\beta$-glucan than in the remaining samples $(\mathrm{p} \leq 0.05)$. Atypical aromas were not detected. The applied $\beta$-glucans and other polysaccharides can mask the characteristic milky aroma, but this effect is determined by the content level and purity of the applied additive.

The most significant changes in the sensory attributes of the analyzed ice cream were noted in the analysis of texture and mouthfeel. A statistical analysis of mouthfeel revealed differences in three out of the eight evaluated descriptors. The addition of (1-3) $\beta$-glucan led to a significant increase in the gumminess and viscosity of ice cream. The relevant increase was higher in the samples containing $1 \%$ of $\beta$-glucan than in the samples containing $0.5 \%$ of $\beta$-glucan. Mouth coating, described as a sensation of having a slick coating on the tongue and other mouth surfaces, was most intense in the sample containing $1 \%$ of bacterial $\beta$-glucan. The addition of $\beta$-glucans had no significant effect on the taste of ice cream. The texture analysis revealed that the evaluated ice cream samples did not differ significantly in firmness, sandiness, fluffiness, or uniformity $(\mathrm{p}>0.05)$. The control sample was characterized by the lowest ropiness, sogginess and creaminess. The addition of $\beta$-glucans positively affected the creaminess of consistency. The application of (1-3) $\beta$-glucan resulted in higher ropiness in comparison with other samples. Regardless of its addition and structure, $\beta$-glucans increased sogginess in all experimental samples. Creaminess generally increases in response to the use of stabilizers [Bahramparvar \& Tehrani, 2011], and it is associated with a decrease in the size of polysaccharide crystals that interact and produce a fatty mouthfeel [Franck, 2002]. In turn, ropiness and sogginess increase with a rise in viscosity that accompanies the application of $\beta$-glucans. Similar results were reported in the rheological analyses carried out by Florowska et al. [2013]. Ice cream viscosity increased with a rise in the content level of $\beta$-glucans, which is consistent with the findings of Soukolis et al. [2009]. The increase in viscosity also contributed to the presence of mouth-coating. The ob-
TABLE 3. Mean values of sensory attributes of ice cream with an addition of $\beta$-glucans.

\begin{tabular}{|c|c|c|c|c|c|c|c|}
\hline \multirow{3}{*}{\multicolumn{2}{|c|}{$\begin{array}{l}\text { Ice cream } \\
\beta \text {-Glucan structure } \\
\beta \text {-Glucan content }\end{array}$}} & \multirow{3}{*}{$\begin{array}{c}\begin{array}{c}\text { Control } \\
\text { (FF) }\end{array} \\
0 \% \\
\end{array}$} & \multicolumn{4}{|c|}{ Experimental (LF) } & \multirow{3}{*}{ p-Values } \\
\hline & & & \multicolumn{2}{|c|}{$\begin{array}{l}(1-3)(1-4) \\
\beta \text {-Glucans }\end{array}$} & \multicolumn{2}{|c|}{$\begin{array}{c}(1-3) \\
\beta \text {-Glucans }\end{array}$} & \\
\hline & & & $0.5 \%$ & $1 \%$ & $0.5 \%$ & $1 \%$ & \\
\hline \multicolumn{8}{|c|}{ Sensory attributes by group } \\
\hline \multirow{4}{*}{ 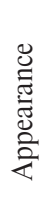 } & Color intensity & 2.1 & 2.3 & 2.4 & 2.4 & 2.5 & $>0.05$ \\
\hline & Atypical color & 1.0 & 1.0 & 1.0 & 1.0 & 1.0 & $>0.05$ \\
\hline & $\begin{array}{l}\text { Color } \\
\text { uniformity }\end{array}$ & 4.1 & 4.1 & 4.1 & 4.1 & 4.1 & $>0.05$ \\
\hline & Discoloration & 1.0 & 1.0 & 1.0 & 1.0 & 1.0 & $>0.05$ \\
\hline \multirow{3}{*}{ 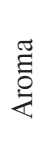 } & Milky & $3.1^{\mathrm{a}}$ & $3.1^{\mathrm{a}}$ & $2.4^{b}$ & $2.4^{\mathrm{b}}$ & $2.4^{\mathrm{b}}$ & 0.029 \\
\hline & Sweet & $2.5^{\mathrm{a}}$ & $2.4^{\mathrm{a}}$ & $2.3^{\mathrm{a}}$ & $2.1^{\mathrm{ab}}$ & $1.8^{\mathrm{b}}$ & 0.032 \\
\hline & Atypical & 1.0 & 1.0 & 1.0 & 1.0 & 1.0 & $>0.05$ \\
\hline \multirow{7}{*}{ 氮 } & Firmness & 3.3 & 3.1 & 3.4 & 3.4 & 3.3 & $>0.05$ \\
\hline & Sandiness & 1.8 & 2.0 & 1.8 & 1.8 & 1.8 & $>0.05$ \\
\hline & Ropiness & $1.8^{\mathrm{b}}$ & $1.8^{\mathrm{b}}$ & $2.3^{\mathrm{ab}}$ & $2.4^{\mathrm{a}}$ & $2.8^{\mathrm{a}}$ & 0.002 \\
\hline & Fluffiness & 3.0 & 2.3 & 2.6 & 2.4 & 2.6 & $>0.05$ \\
\hline & $\begin{array}{l}\text { Texture } \\
\text { uniformity }\end{array}$ & 3.6 & 3.6 & 3.6 & 3.6 & 3.5 & $>0.05$ \\
\hline & Sogginess & $1.8^{\mathrm{b}}$ & $2.3^{\mathrm{ab}}$ & $2.5^{\mathrm{a}}$ & $2.5^{\mathrm{a}}$ & $2.8^{\mathrm{a}}$ & 0.011 \\
\hline & Creaminess & $2.1^{\mathrm{b}}$ & $2.6^{\mathrm{ab}}$ & $3.0^{\mathrm{a}}$ & $3.1^{\mathrm{a}}$ & $3.1^{\mathrm{a}}$ & 0.027 \\
\hline \multirow{8}{*}{ 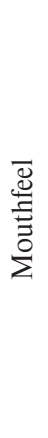 } & Melting & 3.1 & 3.5 & 3.0 & 2.9 & 2.9 & $>0.05$ \\
\hline & Greasiness & 2.5 & 2.6 & 2.6 & 3.0 & 3.1 & $>0.05$ \\
\hline & Firmness & 2.5 & 2.3 & 2.3 & 2.3 & 2.6 & $>0.05$ \\
\hline & Gumminess & $1.0^{\mathrm{c}}$ & $1.0^{\mathrm{c}}$ & $1.0^{c}$ & $2.3^{\mathrm{b}}$ & $2.8^{\mathrm{a}}$ & 0.000 \\
\hline & $\begin{array}{l}\text { Ice } \\
\text { crystallization }\end{array}$ & 1.0 & 1.0 & 1.0 & 1.0 & 1.0 & $>0.05$ \\
\hline & Wateriness & 2.4 & 2.6 & 2.3 & 2.3 & 2.3 & $>0.05$ \\
\hline & Mouth coating & $1.0^{\mathrm{c}}$ & $1.9^{\mathrm{b}}$ & $2.4^{b}$ & $2.5^{\mathrm{b}}$ & $3.5^{\mathrm{a}}$ & 0.000 \\
\hline & Viscosity & $1.8^{\mathrm{c}}$ & $2.0^{\mathrm{c}}$ & $2.3^{\mathrm{bc}}$ & $2.8^{\mathrm{b}}$ & $3.5^{\mathrm{a}}$ & 0.000 \\
\hline \multirow{6}{*}{ 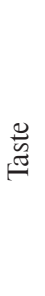 } & Milky & 3.8 & 3.1 & 2.9 & 3.0 & 3.0 & $>0.05$ \\
\hline & Creamy & 3.1 & 3.1 & 3.0 & 2.9 & 2.6 & $>0.05$ \\
\hline & Powdered milk & 3.8 & 3.6 & 3.5 & 3.5 & 3.8 & $>0.05$ \\
\hline & Sweet & 3.8 & 3.9 & 3.9 & 3.9 & 4.1 & $>0.05$ \\
\hline & Cooked & 2.3 & 2.3 & 2.1 & 1.9 & 1.8 & $>0.05$ \\
\hline & Atypical taste & 1.0 & 1.0 & 1.0 & 1.0 & 1.0 & $>0.05$ \\
\hline
\end{tabular}

FF - Full fat; LF - Low fat. a,b,c_- Mean values in a row with different letters are different at $p \leq 0.05$. Scale from 1 to 5 , where 1 denoted the $a b-$ sence of a given attribute, and 5 denoted attribute of extreme intensity.

served increase in gumminess resulted from the application of a higher content level of the stabilizer [Karaca et al., 2009], in particular in ice cream with $1 \%$ addition of (1-3) $\beta$-glucan. The applied $\beta$-glucans did not led to significant changes in ice cream taste, and they conformed to the requirements imposed on food stabilizers [Kilara \& Chandan, 2008]. However, higher sensory viscosity can eliminate the application of bacterial $\beta$-glucans from commercial ice cream production. On the other hand, an increase in the creaminess of ice cream 
containing $\beta$-glucans and other polysaccharides increase the application of these additives as fat replacers [Karaca et al., 2009]. Nevertheless, consumer acceptance of increased viscosity, gumminess, and creaminess of ice cream produced with the addition of $\beta$-glucans should be tested before these additives are applied (Table 3 ).

\section{CONCLUSIONS}

The results of this study indicate that the functional properties of ice cream are influenced by the structure and content level of the $\beta$-glucans. The use of glucans resulted in shortening the melting time of ice cream and increasing its aeration. Compared to (1-3)(1-4) $\beta$-glucan, (1-3) $\beta$-glucan significantly affects hardness, viscosity index, and cohesion. Similarly, significant differences in rheological properties (consistency index, flow behavior index) and sensory attributes were observed between the ice cream produced with the addition of (1-3) $\beta$-glucan with a linear structure and (1-3)(1-4) $\beta$-glucan with a branched structure. More significant variations in the above parameters were noted in the samples containing $1 \%$ of $\beta$-glucans than in those containing $0.5 \%$ of $\beta$-glucans. The application of (1-3)(1-4) $\beta$-glucan isolated from oats supported the production of low-calorie ice cream with functional properties that most closely resembled the control ice cream (full-fat, with stabilizing substances). The sensory attributes of ice cream containing (1-3)(1-4) $\beta$-glucan were also more similar to those of control ice cream.

\section{RESEARCH FUNDING}

Project financially supported by Minister of Science and Higher Education in the range of the program entitled "Regional Initiative of Excellence" for the years 2019-2022, Project No. 010/RID/2018/19, amount of funding 12.000.000 PLN and statutory research, Project No. 17.610.003-110.

\section{ACKNOWLEDGEMENTS}

We are grateful to Eng. K. Bobek, MSc. Eng. E. Ryszewska, MSc. Eng. E. Stalewska for their help in performing analysis.

\section{REFERENCES}

1. Abdel-Haleem, A.M.H., Awad, R.A. (2015). Some quality attributes of low-fat ice cream substituted with hulless barley flour and barley $\beta$-glucan. Journal Food Science \& Technology, 52(10), 6425-6434.

2. Akalin, A.S., Erisir, D. (2008). Effects of inulin and oligofructose on the rheological characteristics and probiotic culture survival in low-fat probiotic ice cream. Journal of Food Science, 73(4), M184-M188.

3. Akesowan, A. (2009). Influence of soy protein isolate on physical and sensory properties. Thai Journal of Agricultural Science, 42(1), 1-6.

4. Aljewicz, M., Tonska, E., Juskiewicz, J., Cichosz, G. (2018). The influence of product acidity and $\beta$-glucans isolated from various sources in the mineral composition and the mechanical and microstructural properties of the femur in growing Wistar rats. Journal of Functional Foods, 44, 191-200.

5. AOAC Official Method 941.08. (2000). Total solids in ice cream and frozen desserts.

6. Bahramparvar, M., Tehrani, M.M. (2011). Application and functions of stabilizers in ice cream. Food Reviews International, 27, 389-407.

7. Bolliger, S., Goff, H.D., Tharp, B.W. (2000). Correlation between colloidal properties of ice cream mix and ice cream. International Dairy Journal, 10, 303-309.

8. Burkus, Z., Temelli, F. (2000).Stabilization of emulsions and foams using barley $\beta$-glucan. Food Research International, $33,27-33$.

9. Dervisoglu, M., Yazici, F. (2006). The effect of citrus fibre on the physical, chemical and sensory properties of ice cream. Journal of Food Science and Technology, 1, 159-164.

10. Dymitrów, I., Jasińska, M., Mituniewicz-Małek, A., Trzciński, J. (2012). Whey protein concentrates and whey-fat preparations as replacements for milk powder in low-frozen ice cream, Acta Agrophysica, 19(1), 37-50.

11. EN ISO 13299:2016-05E Sensory analysis — Methodology General guidance for stablishing a sensory profile.

12. EN ISO 8586:2014-03. Sensory analysis. General guidelines for the selection, training and monitoring of selected assessors and expert sensory assessors.

13. EN ISO 8968-1:2014 Milk and milk products — Determination of nitrogen content - Part 1: Kjeldahl principle and crude protein calculation.

14. Florowska, A., Wójcik, E., Florowski, T., Dłużewska, E. (2013). Effect of fiber addition on selected parameters of ice cream quality. Zeszyty Problemowe Postępów Nauk Rolniczych, 574, 11-18 (in Polish).

15. Franck, A. (2002). Technological functionality of inulin and oligofructose. British Journal of Nutrition, 87, S287-S291.

16. Granger, C., Legerb, A., Barey, P., Langendorff, V.M. (2005). Can sell Influence of formulation on the structural networks in ice cream. International Dairy Journal, 15(3), 255-262.

17. Güzeler, N., Kacar, A., Say D. (2011). Effect of milk powder, maltodextrin and polydextrose use on physical and sensory properties of low calorie ice cream during storage. Academic Food Journal, 7, 6-12.

18. Hu, X., Zhao, J., Zhao, Q., Zheng, J. (2015). Structure and characteristic of $\beta$-glucan in cereal: a review. Journal of Food Processing and Preservation, 39, 3145-3153.

19. Javidi, F., Razavi, S.M.A. (2018). Rheological, physical and sensory characteristics of light ice cream as affected by selected fat replacers. Journal of Food Measurement and Characterization, 12(3), 1872-1884.

20. Javidi, F., Razavi, S.M., Behrouzian, F., Alghooneh, A. (2016). The influence of basil seed gum, guar gum and their blend on the rheological, physical and sensory properties of low fat ice cream. Food Hydrocolloids, 52, 625-633.

21. Kanagasabapathy, G., Malek, S.N., Mahmood, A.A., Chua, K.H., Vikineswary, S., Kuppusamy, U.R. (2013). $\beta$-Glucan-rich extract from Pleurotussajor-caju (Fr.) Singer prevents obesity and oxidative stress in C57BL/6J mice fed on a high-fat diet. Evidence-Based Complementary and Alternative Medicine, 2013, art. no. 185259 . 
22. Karaca, B.O., Guven, M., Kaya, S., Kahyaoglu, T. (2009). The functional, rheological and sensory characteristics of ice creams with various fat replacers. International Journal of Dairy Technology, 62, 93-99.

23. Kilara, A., Chandan, R.C. (2008). Ice cream and frozen desserts. In Chandan, R. C., Kilara, A., Shah, N. (Eds.), Dairy Processing \& Quality Assurance, New Delhi, India: Wiley-Blackwell, pp. 364-365.

24. Patent application. (2020). P.418827. Aljewicz M., Baranowska M. Sposób wytwarzania prozdrowotnych mlecznych napojów fermentowanych (Method of producing pro-healthy fermented milk beverages), Urzad Patentowy Rzeczypospolitej Polskiej, 2020 (in Polish).

25. Rezaei, R., Khomeiri, M., Kashaninejad, M., Mazaheri-Tehrani, M., Aalami, M. (2015). Effect of resistant starch and aging conditions on the physicochemical properties of frozen soy yogurt. Journal of Food Science \& Technology, 52(12), 8164-8171.

26. Rinaldi, M., Dall'Asta, C., Paciulli, M., Guizzetti, S., Barbanti, D., Chiavaro, E. (2014) Innovation in the Italian ice cream production: effect of different phospholipid emulsifiers. Dairy Science and Technology, 94, 33-49.

27. Roland, A.M., Phillips, L.G., Boor, K.J. (1999). Effects of fat content on the sensory properties, melting, color, and hardness of ice cream. Journal of Dairy Science, 82, 32-38.

28. Sharma, M., Singh, A.K., Yadav, D.N. (2017). Rheological properties of reduced fat ice cream mix containing octenylsuccinylated pearl millet starch. Journal of Food Science \& Technology, 54(6), 1638-1645.
29. Şimşekli, N., Doğan, I.S. (2015). Effect of addition of cereal based beta-glucan on technological and functional properties of foods. Turkish Journal of Agriculture-Food Science and Technology, 3(4), 190-195.

30. Soukoulis, C., Rontogianni, E., Tzia, C. (2010). Contribution of thermal, rheological and physical measurements to the determination of sensorially perceived quality of ice cream containing bulk sweeteners. Journal of Food Engineering, 100(4), 634-641.

31. Soukoulis, Ch., Lebesi, D., Tzia, C. (2009). Enrichment of ice cream with dietary fibre: Effects on rheological properties, ice crystallization and glass transition phenomena. Food Chemistry, $115(2), 665-671$.

32. Stone, B.A. (2009). Chemistry of $\beta$-glucans. In Bacic, A., Fincher, G.B., Stone, B.A., Chemistry, Biochemistry, and Biology of $1-3 \beta$-Glucans and Related polysaccharides, USA, Elsevier, pp. 5-46.

33. Surapat, S., Rugthavon, P. (2003). Use of modified starch as fat replacer in reduced fat coconut milk ice cream. Kasetsart Journal Natural Science, 37(4), 484-492.

34. Survase, S.A., Saudagar, P.S., Bajaj, J.B., Singhal, R.S. (2007). Scleroglucan: Fermentative production, downstream processing and applications. Food Technology and Biotechnology, 45(2), 107-118.

Submitted: 13 February 2020. Revised: 9 and 20 April 2020. Accepted: 21 April 2020. Published on-line: 9 June 2020. 